\title{
Perbedaan Fear Of Success Ditinjau Dari Status Pernikahan Pada Wanita Karier
}

\author{
Triana Octaviani Pita \\ Berta Esti Ari Prasetya \\ Fakultas Psikologi Universitas Kristen Satya Wacana \\ trianaocta14@gmail.com, bertaprasetya@gmail.com
}

\begin{abstract}
Abstrak
Wanita karier dapat mengalami fear of success yang cenderung disebabkan oleh beberapa faktor, salah satunya adalah status pernikahan yaitu menikah dan belum menikah. Penelitian ini bertujuan untuk menguji adanya perbedaan fear of success antara dua kelompok. Subjek dalam penelitian ini adalah karyawati bank-bank yang berada di daerah Salatiga sebanyak 76 orang (38 menikah dan 38 belum menikah), dipilih dengan teknik accidental sampling. Data dikumpulkan dengan skala fear of success yang dibuat oleh peneliti berdasarkan aspek-aspek fear of success oleh Horner (dalam Berkowitz, 1980). Uji Hipotesis dilakukan dengan menggunakan $t$-test yang menunjukkan angka $t$ sebesar 5,862 dengan signifikansi $0,000(p<0,05)$. Hasil hipotesis ini diterima yakni ada perbedaan fear of success ditinjau dari status pernikahan pada wanita karier, dimana wanita yang sudah menikah memiliki fear of success lebih tinggi dibandingkan dengan wanita belum menikah.
\end{abstract}

Kata kunci: fear of success, status pernikahan, wanita karier.

\begin{abstract}
Career woman can experience the fear of success that tend to be caused by several factors, one factor is the marital status of married and unmarried. This study aims to examine the differences in fear of success between the two groups. Subjects in this study is an employee of the banks that are in the area Salatiga many as 76 people (38 married and 38 unmarried), selected by accidental sampling technique. Scale Data collected by fear of success made by researchers based aspects of fear of success by Horner (in Berkowitz, 1980). Hypothesis test conducted using t-test showed the number $t$ of 5.862 with a significance of $0.000(p<0.05)$. The results of this hypothesis is accepted that there is a difference fear of success in terms of marital status on a woman's career.
\end{abstract}

Keywords: fear of success, marital status, career woman. 


\section{PENDAHULUAN}

Kondisi wanita saat ini bila melihat pergeseran budaya dari masyarakat tradisional ke masyarakat modern berdampak pada terbukanya kesempatan bagi para wanita untuk bekerja dan mengejar kariernya. Seiring berjalannya waktu dapat dilihat semakin banyak wanita yang menduduki posisi tertentu di berbagai instansi maupun perusahaan. Survei yang dilakukan oleh Thornton (2017) menunjukkan bahwa wanita Indonesia termasuk yang tertinggi di dunia untuk mengisi posisi di perusahaan, hal tersebut menunjukkan model karier yang semakin berkembang sejalan dengan perkembangan waktu. Berdasarkan data dari Dinas Kependudukan dan Pencatatan Sipil Kota Salatiga tahun 2011, jumlah wanita di kota Salatiga lebih banyak dari laki-laki diharapkan dapat berkontribusi dalam pekerjaan untuk meningkatkan kualitas sumber daya di Salatiga.

Dewasa ini wanita yang bekerja dan berkarier diharapkan tidak hanya sekadar bekerja tetapi memiliki kedudukan yang berarti ditempat kerjanya, berprestasi dan berani menerima tantangan dalam bekerja. Mereka juga diharapkan memiliki dedikasi penuh pada profesi yang ditekuninya, sehingga dapat mengembangkan kemampuannya untuk memimpin, serta terlibat aktif dalam penyampaian ide-ide, pemikiran maupun pengambilan keputusan (Horner, 1972).

Sejalan dengan keberhasilan dalam berkarier, wanita sering diliputi perasaan ketakutan akan keberhasilan yang lebih dikenal dengan istilah fear of success, diartikan sebagai ketakutan seorang wanita untuk berprestasi atau meraih sukses karena kemungkinan akan diterimanya konsekuensi negatif dari masyarakat akibat sukses yang diraihnya (Horner, 1970).

Wanita yang mengalami fear of success akan sulit untuk menjalankan pekerjaannya. Ada kecemasan bagi wanita bekerja yang sudah menikah bahwa keluarga akan terlantar apabila sukses dalam berkarier, sehingga ia enggan meraih karier yang lebih tinggi. Adanya pandangan ini pada seorang wanita bekerja memunculkan adanya motivasi menghindari sukses (motivation to avoid success) yang mengakibatkan ia tidak dapat mengembangkan potensinya secara optimal, akibatnya juga akan terhambat untuk meraih prestasi kerja yang maksimal (Yusnita, 2010).

Sedangkan wanita karier yang belum menikah memiliki kebebasan dengan tidak terikat pada pernikahan sehingga merasa lebih leluasa dalam melakukan aktivitasnya (Santrock, 2002). Untuk memetakan data, peneliti melakukan wawancara singkat pada 13 Januari 2017 kepada enam wanita yang bekerja, tiga wanita yang sudah menikah dan tiga lagi belum menikah. Wanita bekerja yang belum menikah rata-rata mengungkapkan berani berkarier di perusahaan dan bersaing dengan rekan kerjanya, ada pula yang bekerja di luar kota hanya untuk meniti karier. Sedangkan pada tiga wanita pekerja yang sudah menikah membatasi pekerjaannya bahkan ada yang mengungkapkan menolak promosi kerja karena alasan kurang didukung oleh suami. Ada pula yang enggan dipindahkan ke cabang kantor 
lain karena alasan takut urusan keluarga dan rumah tangga menjadi terbengkalai serta takut menelantarkan anak karena jarak kantor lain sangat jauh dari rumah.

Dapat disimpulkan bahwa wanita yang belum menikah masih ingin memaksimalkan kemampuan yang dimilikinya, sedangkan wanita pekerja yang sudah menikah memilih bekerja namun kurang memaksimalkan kemampuan yang dimilikinya dikarenakan rasa takut dan cemas dalam berkarier dengan berbagai pertimbangan dan konsekuensi negatif dari suami maupun keluarga. Hal tersebut menggambarkan bahwa wanita karier yang belum menikah memiliki kesempatan dan keinginan untuk memaksimalkan kemampuannya dalam berkarier dibandingkan dengan wanita yang sudah menikah karena memiliki kecemasan berhubungan dengan suami maupun anak dalam perjalanan kariernya.

Sebelumnya, penelitian mengenai fear of success ditinjau dari status pernikahan (studi komparasi pada wanita pekerja) yang dilakukan oleh Prihandhany (2015) menunjukkan hasil bahwa wanita pekerja yang sudah menikah memiliki tingkat fear of success yang lebih tinggi dibandingkan dengan wanita pekerja yang belum menikah.

Penelitian dari Lestari (2017) menemukan terdapat hubungan positif antara konflik peran ganda dengan fear of success, artinya semakin tinggi konflik peran ganda yang dialami maka semakin tinggi pula fear of success-nya. Penelitian Kamilatus (2013) mendapatkan hasil bahwa terdapat perbedaan fear of success signifikan yang dialami wisudawan yang belum menikah dengan yang sudah menikah, dimana fear of success yang sudah menikah lebih tinggi dari pada tingkat fear of success yang belum menikah.

Kemudian penelitian dari Pusparini (2009) mendapatkan hasil tidak adanya perbedaan fear of success antara wanita karier usia dewasa awal ditinjau dari status pernikahannya, salah satu faktor yang memengaruhi tidak adanya perbedaan adalah skala yang bersifat social desirebility. Sejalan dengan penelitian Sukainah (2003), yang menunjukkan bahwa tidak ada perbedaan fear of succes wanita karier yang sudah menikah dan belum menikah, hal tersebut diungkap oleh peneliti karena kemungkinan pengisian data yang tidak diobservasi dan tidak sepenuh hati serta kemungkinan ada hubungannya dengan kondisi kariernya saat itu. Maka dari itu peneliti akan melakukan penelitian secara mendalam dengan mengajukan hipotesis "Ada perbedaan fear of success ditinjau dari status pernikahan pada wanita karier."

\section{METODE PENELITIAN}

\section{Jenis Penelitian}

Jenis penelitian yang digunakan adalah jenis penelitian komparatif. Jenis penelitian ini dilakukan untuk membandingkan persamaan dan perbedaan dua atau lebih fakta-fakta dan sifat-sifat objek yang diteliti berdasarkan kerangka pemikiran tertentu (Sugiyono, 2011). 


\section{Populasi dan Sampel}

Populasi dalam penelitian ini adalah wanita karier menikah dan belum menikah yang bekerja di 11 bank di daerah Salatiga. Selanjutnya sampel yang digunakan dalam penelitian yakni wanita karier menikah sejumlah 38 orang kemudian yang belum menikah sejumlah 38 orang dengan karakteristik: wanita karier yang sudah menikah dan belum menikah, usia 18 40 tahun, pendidikan minimal D-3. Teknik pengambilan sampel yang digunakan adalah accidental sampling yaitu pengambilan sampel pada siapa saja yang kebetulan bertemu dengan peneliti, dapat digunakan sebagai sampel apabila orang yang ditemui cocok sebagai sumber data (Sugiyono, 2011).

\section{Teknik Pengumpulan Data}

Skala yang digunakan yaitu skala fear of success yang dibuat oleh peneliti berdasarkan aspek-aspek fear of success yang dikemukakan oleh Horner (dalam Berkowitz, 1980) yakni: 1. Loss of Social Self-Esteem (Ketakutan akan penolakkan sosial), 2. Loss of Feminity (Berhubungan dengan femininitas atau normalitas), 3. Social Rejection (Pengingkaran), dengan model Skala Likert yang terdiri dari pernyataan favourable dan unfavourable terdiri dari empat pilihan jawaban yaitu SS (Sangat Setuju), S (Setuju), TS (Tidak Setuju), STS (Sangat Tidak Setuju). Berdasarkan hasil pengujian reliabilitas dan uji daya diskriminasi pada skala fear of success dilakukan sebanyak dua kali putaran dengan standar koefisien korelasi $\geq 0,30$ (Azwar, 2012). Pada putaran pertama, hasil seleksi aitem dari 55 aitem diperoleh 12 aitem yang gugur dengan koefisien reliabilitas 0,923 . Selanjutnya dilakukan uji kedua dengan 43 aitem yang baik, tidak ditemukan aitem yang gugur dengan koefisien reliabilitas 0,942 yang berarti sangat reliabel. Nilai item correlation total bergerak antara 0,333 sampai 0,711 .

\section{Analisis Data}

Metode statistik yang digunakan dalam penelitian ini adalah teknik statistik 'Uji-t' dengan menggunakan program SPSS for Windows versi 16.0. Penggunaan teknik statistik ini bertujuan untuk mencari perbedaan satu variabel tergantung (Fear of success) antara dua kelompok (Status Pernikahan yaitu menikah dan belum menikah).

\section{HASIL DAN PEMBAHASAN}

\section{Hasil}

\section{A. Analisis Deskriptif}

Untuk menentukan tinggi rendahnya variabel fear of success pada wanita karier yang sudah menikah dan belum, maka digunakan 5 kategori pengelompokkan sebagai berikut: 
Tabel 1. Kriteria skor Fear of success pada Wanita Karier Menikah dan Belum Menikah

\begin{tabular}{ll|llll|llll}
\hline & & \multicolumn{5}{|c|}{ Menikah } & \multicolumn{3}{c}{ Belum Menikah } \\
\hline KATEGORI & INTERVAL & F & $\%$ & MEAN & SD & f & $\%$ & MEAN & SD \\
\hline Sangat Tinggi & $146,2 \leq x<172$ & 0 & $0 \%$ & & & 0 & $0 \%$ & \\
Tinggi & $120,4 \leq x<146,2$ & 0 & $0 \%$ & & & 0 & $0 \%$ & & \\
Sedang & $94,6 \leq x<120,4$ & 25 & $66 \%$ & 94,89 & 10,94 & 0 & $0 \%$ & 77,03 & 12,59 \\
Rendah & $68,8 \leq x<94,6$ & 12 & $32 \%$ & & & 3 & $79 \%$ & & \\
Sangat Rendah & $43 \leq x<68,8$ & 1 & $3 \%$ & & & 8 & $21 \%$ & \\
\hline
\end{tabular}

Data di atas menunjukkan bahwa tingkat fear of success pada wanita karier yang sudah menikah berbeda-beda yakni pada kategori sangat rendah didapatkan presentase sebesar $3 \%$, kategori rendah sebesar $32 \%$, kategori sedang sebesar $66 \%$. Rata-rata (mean) yang diperoleh adalah 94,89 . Berdasarkan mean yang diperoleh, fear of success yang dimiliki wanita karier sudah menikah berada pada kriteria yang sedang. Kemudian pada kelompok wanita karier belum menikah pada kategori sangat rendah sebesar $21 \%$, kategori rendah sebesar $79 \%$. Rata-rata (mean) yang diperoleh adalah 77,03. Berdasarkan mean yang diperoleh, fear of success yang dimiliki wanita karier belum menikah berada pada kriteria yang rendah.

\section{B. Hasil Uji Asumsi \\ I. Hasil Uji Normalitas}

Uji normalitas pada penelitian ini menggunakan Kolmogorov-Smirnov Test untuk mengetahui normal atau tidaknya distribusi data pada masing-masing kelompok. Berdasarkan hasil uji normalitas data menunjukkan dari kelompok wanita karier sudah menikah menujukkan nilai K-S-Z sebesar 0,888 dengan nilai sig. $=0,410(p>0,05)$, dan kelompok wanita karier belum menikah memiliki nilai K-S-Z sebesar 0,631 dengan nilai sig. $=0,820(\mathrm{p}$ $>0,05)$ dengan demikian kedua kelompok tersebut berdistribusi normal.

\section{Hasil Uji Homogenitas}

Selanjutnya dilakukan pengujian homogenitas, menunjukkan bahwa nilai koefisien Levene Test sebesar 1,515 dengan signifikansi sebesar 0,222. Oleh karena nilai signifikansi lebih dari 0,05, maka dapat dikatakan bahwa data tersebut homogen.

\section{Hasil Uji Hipotesis}

Untuk mengetahui apakah terdapat perbedaan fear of success ditinjau dari status pernikahan pada wanita karier, maka digunakan rumus Independent Sampel Test dengan menggunakan SPSS 16.0 for Windows. Data yang diperoleh dalam penelitian ini diolah menggunakan Uji-t. Uji ini digunakan untuk melihat apakah rata-rata satu sampel berbeda dengan sampel lainnya. Jika $p<0,05$ maka dapat dikatakan ada perbedaan fear of success 
ditinjau dari status pernikahan pada wanita karier, namun jika $p>0,05$ maka tidak ada perbedaan fear of success ditinjau dari status pernikahan pada wanita karier. Setelah dilakukan analisis data didapatkan hasil sebagai berikut:

Hasil perhitungan Independent Sampel Test pada tabel di atas menunjukkan bahwa nilai signifikansi untuk perbedaan fear of success ditinjau dari status pernikahan pada wanita karier (equal variance assumed) memiliki nilai t-test sebesar 5,862 dengan signifikansi 0,000 atau $p<0,05$ yang berarti terdapat perbedaan fear of success ditinjau dari status pernikahan pada wanita karier, dimana wanita yang sudah menikah memiliki fear of success lebih tinggi.

Berdasarkan hasil penelitian tentang perbedaan fear of success ditinjau dari status pernikahan pada wanita karier di Salatiga, didapatkan hasil perhitungan Independent Sampel Test sebesar 5,862 dengan signifikansi 0,000 ( $p<0,05)$. Hal ini menunjukkan bahwa hipotesis diterima, artinya ada perbedaan signifikan fear of success ditinjau dari status pernikahan pada wanita karier di Salatiga.

Namun pada perhitungan uji komparatif Uji-t dengan bantuan SPSS 16.0 didapatkan mean dari kelompok wanita karier yang sudah menikah sebesar 94,89 dengan sig. $=0,000(p$ $<0,05)$. Kemudian mean kelompok wanita karier yang belum menikah sebesar 77,03 dengan sig. $=0,000(p<0,05)$. Hasil tersebut menunjukkan bahwa terdapat perbedaan fear of success antara wanita karier menikah dan belum menikah dengan hasil rata-rata fear of success wanita karier menikah lebih tinggi daripada wanita karier yang belum menikah.

Pada hasil penelitian apabila dilihat dari penggolongan kategori fear of success pada wanita karier sudah menikah dan belum menikah, kelompok wanita karier sudah menikah didapatkan $66 \%$ fear of success pada kategori sedang, 32\% untuk kategori rendah dan $3 \%$ untuk kategori fear of success sangat rendah. Sedangkan pada kelompok wanita karier belum menikah mendapat $79 \%$ pada kategori fear of success rendah, sisanya $21 \%$ pada kategori fear of success sangat rendah. Apabila dilihat dari rata-rata keseluruhan pada tiap kategori maka kelompok menikah berada pada kategori fear of success yang sedang, sedangkan kelompok yang belum menikah berada pada kategori fear of success rendah.

Pada wanita karier yang belum menikah masuk pada kriteria fear of success yang rendah, penulis mencoba menjelaskan bahwa kemungkinan wanita karier yang belum menikah sebenarnya cenderung tidak memiliki fear of success, hal tersebut dapat terjadi karena status yang masih single belum memiliki tuntutan dalam rumah tangga sehingga dapat mampu fokus bekerja. Namun, wanita juga memiliki tuntutan lain yang menyebabkan terganggunya pekerjaan. Seperti yang diketahui pada kelompok wanita karier yang belum menikah pada penelitian ini cenderung memenuhi kebutuhan ekonomi untuk kehidupannya sendiri, serta adanya prioritas-prioritas kehidupan lainnnya yang perlu dicukupi oleh dirinya sendiri, tak jarang ada beberapa wanita yang belum menikah melakukan pekerjaannya dan 
berkarier karena membantu keluarga dan orang tuanya (Wulandari, Nursalam \& Ibrahim, 2016).

Hal tersebut yang melatarbelakangi mengapa wanita belum menikah memikirkan karier dan pekerjaannya. Pada wanita karier yang belum menikah diperoleh data penelitian adanya kecenderungan keinginan untuk berprestasi yang cukup tinggi, hal tersebut menjadi salah satu alasan mengapa fear of success cenderung berada pada kategori rendah (Adibah, 2008). Fear of success yang berada pada taraf rendah sampai sedang juga dapat disebabkan oleh tingginya tingkat pendidikan pada kedua kelompok subjek pada penelitian ini yakni sebagian besar lulusan S-1 dimana dengan tingkat pendidikan juga merubah cara pandang dan pola pikir wanita, seperti penelitian Dahesihsari \& Seniati (2002) menemukan tingkat fear of success yang berbeda antar tingkat pendidikan dimana semakin tinggi tingkat pendidikan, maka tingkat fear of success semakin rendah.

\section{SIMPULAN DAN SARAN}

\section{SIMPULAN}

Berdasarkan hasil penelitian dan uraian yang telah disampaikan, maka dapat ditarik kesimpulan sebagai berikut:

1. Terdapat perbedaan fear of success yang signifikan ditinjau dari status pernikahan pada wanita karier di Salatiga, dimana fear of success wanita karier menikah lebih tinggi daripada wanita karier yang belum menikah.

2. Berdasarkan nilai rata-rata (mean) yang diperoleh pada kelompok wanita karier menikah diperoleh nilai sebesar 94,89 yang berada pada kategori sedang.

3. Berdasarkan nilai rata-rata (mean) yang diperoleh pada kelompok wanita karier belum menikah diperoleh nilai sebesar 77,03 yang berada pada kategori rendah.

\section{SARAN}

Berdasarkan hasil penelitian yang telah dilakukan, serta mengingat masih banyaknya keterbatasan dalam penelitian ini, maka peneliti memberikan beberapa saran sebagai berikut:

1. Saran bagi Wanita Karier

Diharapkan wanita karier tetap mencapai prestasi lebih tinggi dalam pekerjaannya, memaksimalkan kemampuan dalam pekerjaan serta menekan ketakutan yang muncul dalam diri dan membuka peluang dalam mencapai kesuksesan. Diharapkan adanya dukungan lingkungan dan pasangan khususnya untuk wanita karier yang sudah menikah, agar fear of success dapat diatasi dengan baik.

\section{Saran bagi Perusahaan atau instansi terkait}

Diharapkan bagi pihak perusahaan atau instansi agar tetap memberikan pekerjaan kepada wanita dan perlu memperhatikan dampak status pernikahan wanita karier. Selain itu juga dapat mensosialisasikan program pengembangan diri wanita, sehingga para wanita 
dapat menyadari kemampuan dan potensi yang dimilikinya dengan begitu wanita dapat terus berkarier bagi perusahaan.

3. Saran bagi Peneliti selanjutnya

Peneliti selanjutnya dapat melakukan kontrol subjek baik dalam kelas sosial atau faktor lainnya yang memengaruhi fear of success, serta penambahan pertanyaan di dalam skala mengenai alasan utama mengapa wanita berkarier dan ketakutan apa yang sering muncul sehingga dapat diketahui penyebab wanita karier cenderung mengalami fear of success dan sebaliknya. Perlunya penambahan sampel penelitian agar penelitian dapat digeneralisasikan.

\section{DAFTAR PUSTAKA}

Adibah, P. (2008). Hubungan antara Motivasi Berprestasi dengan Fear of Success pada Wanita Bekerja Dewasa Muda. Skripsi. Universitas Gunadarma.

Azwar, S. (1999). Penyusunan Skala Psikologi. Yogyakarta: Pustaka Pelajar.

Data Kependudukan dan Pencatatan Sipil Kota Salatiga. (Januari 2011). Salatiga Tentang Penduduk.

Dahesihsari, R., \& Seniati, A. (2002). Hubungan antara Peran Jenis Kelamin Fear of Success dan Kesukubangsaan dengan Komitmen Dosen Perempuan terhadap Organisasi. Anima, Indonesian Psychological Journal, 17, 332-345.

Horner, M. S. (1972). Toward an Understanding of Achievement Related Conflict in Woman. Journal Social Issues, 28, 157-175.

Horner, M.S. (1970). Femininity and Successful Achievement: A Basiclnconsistency. In J.M. Bardwick, E. Douvan, M.S.

Kamilatus, S. S. (2013). Fear of Success pada Sarjana Perempuan Psikologi IAIN Sunan Ampel Surabaya Ditinjau dari Demografi. Undergraduate thesis, UIN Sunan Ampel Surabaya.

Lestari, Y. I. (2017). Fear of Success pada Perempuan Bekerja Ditinjau dari Konflik Peran Ganda dan Hardiness. Jurnal Psikologi. 13, 55-63.

Prihandhany, E. A. (2015). Fear of Success Ditinjau dari Status Pernikahan (Studi Komparasi pada Wanita Pekerja). Skripsi.

Pusparani, V. S. (2009). Perbedaan Fear of Success pada Wanita Karier Usia Dewasa Awal Ditinjau dari Status Pernikahan. Fakultas Psikologi Sanata Darma. Yogyakarta: USD.

Santrock, J. W. (2002). Life Span Development. Jilid II, (ed. ke-5) alih bahasa:Chusairi, S. Psi., Jakarta: Erlangga.

Sukainah, D. (2003). Studi Perbedaan Fear of Success pada Wanita Karir yang Sudah Menikah dengan Wanita Karir yang Belum Menikah di PT. Bank $X$ Surabaya. Undergraduate thesis.

Sugiyono. (2011). Statistika untuk Penelitian. Bandung: Alfabeta. 
Thornton, G. (2017). Woman in Business. International Business Report.

Wulandari, I., Nursalam., Ibrahim, M. (2016). Fenomena Sosial Pilihan Hidup Tidak Menikah Wanita Karier. Jurnal Equilibrium, 2, 67-76.

Yusnita, R,I. (2010). Pengaruh Pengembangan Karir terhadap Konflik - Pekerjaan - Keluarga dan Ketakutan akan Kesuksesan pada Wanita serta Dampaknya pada Prestasi Kerja. Jurnal. 